\title{
Collaborative Learning: A Connected Community Approach
}

\author{
John Rae, Carole Roberts, and Gary Taylor \\ University of Salford, Salford, UK
}

\author{
j.m.rae@salford.ac.uk c.a.roberts@salford.ac.uk \\ g.d.taylor@salford.ac.uk
}

\begin{abstract}
Collaborative Learning in group settings currently occurs across a substantial portion of the UK Higher Education curriculum. This style of learning has many roots including: Enterprise in Higher Education, Action Learning and Action Research, Problem Based Learning, and Practice Based Learning. As such our focus on Collaborative Learning development can be viewed as an evolutionary. This collaborative and active group learning provides the foundation for what can be collectively called connectivist 'Learning Communities'. In this setting a primary feature of a 'Learning Community' is one that carries a responsibility to promote one another's learning.

This paper will outline a developmental collaborative learning approach and describe a supporting software environment, known as the Salford Personal Development Environment (SPDE), that has been developed and implemented to assist in delivering collaborative learning for post graduate and other provision. This is done against a background of much research evidence that group based activity can enhance learning. These findings cover many approaches to group based learning and over a significant period of time.
\end{abstract}

This paper reports on work-in-progress and the features of the environment that are designed to help promote individual and group or community learning that have been influenced by the broad base of research findings in this area.

Keywords: Learning, collaborative learning, learning communities, VLE, connectivity, groups, action learning, learning environment, coaching, mentors, team work, learning technology, knowledge management

\section{Introduction}

The developing HE Environment is being influenced by a number of drivers that require us to address what we teach, how, when and where - and importantly how we support our students'

Material published as part of this publication, either on-line or in print, is copyrighted by the Informing Science Institute. Permission to make digital or paper copy of part or all of these works for personal or classroom use is granted without fee provided that the copies are not made or distributed for profit or commercial advantage AND that copies 1) bear this notice in full and 2) give the full citation on the first page. It is permissible to abstract these works so long as credit is given. To copy in all other cases or to republish or to post on a server or to redistribute to lists requires specific permission and payment of a fee. Contact Publisher@InformingScience.org to request redistribution permission. learning. The drivers include:

i.) The continuing Government pressure to expand the HE experience to $50 \%$ of the population by 2010, notwithstanding the current growth rates are too low to achieve this;

ii.) The increasing financial pressures particularly on home students leading to an increasing 
number of students who are effectively "part-time” but following full-time courses of study;

iii.) The continuing change of status from "accepting student" to that of a fee-paying customer and lifelong learner with growing expectations of service to meet career needs and financial constraints;

iv.) The pressures on further education institutions to continuously improve success rates leading to students being provided with more and more information to complete coursework and pass examinations and thus less likely to develop the skills for lifelong learning or to cope with HE challenges;

v.) The impact of ICT on what is expected by learners and of what can be provided by institutions - and what rethinking of HE organisations has to follow to provide flexible and responsive modes of blended learning with integrated learning support.

Following from this last driver there is an underlying imperative to provide flexible and responsive student support structures, with institution-wide mechanisms that are capable of managing face-to-face, blended and distance learning options. These must increasingly allow students to be able to choose when, where and how they learn. Hence the support must accommodate the full diversity of study patterns and ideally be capable of personalisation to individual student level.

Coupled with the changing nature of students and their demands for flexible learning support, is the ever increasing stress on education for employability, capability and lifelong learning. Given the rapid development of knowledge anyway, we should primarily be striving for learning that lasts and preparing our students for life-long updating with more emphasis on the process of learning.

\section{Meeting the Challenges}

With the increasing emphasis on employability and capability, there is the need for students to learn how to create knowledge, as they will find it created in the real world. This will involve collaboration, consultation, teamwork and connectivism. Bruffee (1999) suggests that probably the most important lesson students should learn during their HE experience is mature, elective interdependence - social maturity with intellectual maturity.

There is a growing awareness that collaborative learning in learning communities during their time in education will help students to improve their critical thinking (Gokhale, 1995) and to learn to work effectively together, an attribute much valued in the real world with benefits to both their professional and personal lives. As Edwin Mason (1971. p. 16) wrote:

"I cannot think of any part or moment of life in which we are not reacting to the presence of other people, or carrying over into relationship with everything else, what we have learned (by no means all of it consciously) from collaborating with other people while exploring the world with them."

But given the increasing tendency for our students to be "part-time” even while following fulltime courses and to be on campus for the minimum time necessary, how can we provide an environment where they can learn collaboratively in learning communities? At Salford our developing approach to this problem is to bring together and apply three essential curriculum elements: current PDP know-how, current collaborative learning practice and a curriculum core for integrating principal subjects with PDP based reflection and planning. An integral part of this proposed approach is the development of a learning management system - the Salford Personal Development Environment (SPDE). By adapting and extending the environment using learning communities connected remotely rather than face-to-face we are striving to simultaneously engage students in 
the real world approach to knowledge creation, promote reflective learning and enhance their ability to learn how to learn.

\section{Collaborative Learning, Learning Communities and Connectivity}

Collaborative learning is a philosophy of teaching in which learners work together on a common goal, exchange their opinions on a subject, clarify the meanings of concepts or jointly address a problem (Hron \& Friedrich, 2003).

As well as preparing students for the "real world", there is evidence that collaborative learning helps students learn better. Richard Light's (1990) studies of Harvard undergraduate education support this assertion. Light reports that dividing students into small groups tends to increase their "enthusiasm and their pursuit of topics to a more advanced level". The Russian psychologist L.S. Vygotsky (Cole, 1978) invented the term "zone of proximal development" which refers to understanding that lies just beyond current knowledge and ability - what we cannot learn on our own but can do with help from friends. Collaborative learning allows the prior knowledge that each brings to the community to be used on the problem at hand and to construct new knowledge from it. Further, collaborative learning has as one of its goals to help students acknowledge disagreement and cope with difficulties within the community. This can be hard but again prepares students for the "real world" experience.

As described by Bruffee (1999) collaborative learning actually has a long history. For example, when Benjamin Franklin was young in the 18th century he organised autonomous learning groups to promote his own informal learning. Up until the 1930s there was continued interest in educational peer influence but then it nearly died out. A revival in the 1960s was followed by another decline in the 70s and 80s. Its value is once again becoming more widely appreciated. Throughout modern times important studies have demonstrated the importance of peer-group influence (e.g. Astin, 1993; Coleman, 1973; Newcomb, 1962; Tang; 1998). Initially Astin had simply concluded that student satisfaction increased if friendships were encouraged but by 1993 he had decided that the peer group produces "some of the strongest and certainly the most widespread effects on student development" and that they seem to "learn course material in greater depth because they are involved in helping to teach it to fellow students”. Indeed Tank found that the characteristics of the learning approach of a collaborating group of students were very similar to the characteristics of a deep approach to learning while students who did not collaborate in their learning displayed characteristics which were typical of a surface approach.

Notwithstanding the growing awareness of the benefits of collaborative learning, it is still frowned upon as part of the educational process by some HE teachers. Hence one factor that may constrain engagement in a learning community can be students' perception of what constitutes a "good" student, namely being independent and clever (Read, Archer, \& Leathwood, 2003). However Thomas Kuhn (1970) asserted that "knowledge is intrinsically the common property of a group or else nothing at all”. Oakeshott (1962) further argued that we can think because we can talk with one another, underlying the importance of conversation. Modern learning technologies have facilitated not only the dissemination of information to individuals but also the ability of groups of individuals in different geographical locations to engage in "conversation”. Thus collaborative learning is now not restricted to situations where individuals can meet face-to-face at the same time and in the same place.

As we have learned in the last 10 - 15 years, asynchronous computer mediated communication whilst overcoming barriers of time and place does not automatically overcome the potentially alienating constraints posed by face-to-face learning environments. Students do not always en- 
gage with the community. Building a sense of belonging is likely to enhance students' motivation and engagement. But a successful critical community of learners will recognise the importance of "cognitive independence" as well as "social interdependence" (Garrison \& Anderson, 2003). Mann (2005) also argues that as well as building a sense of belonging it may be important to consider the learning community as a "communicative event" and to focus more on supporting dialogue within the learning environment.

At Salford we are pursuing a collaborative learning approach to support Salford post graduate and other provision. Our approach places learners on the same footing as tutors thus addressing, at least in part, one of the other factors that may alienate and isolate learners, namely the effects of unequal power relations within a learning community. As will be seen, the use of the SPDE also seeks to support the development of both cognitive independence and social interdependence.

We may further ask whether working within a single community is now sufficient when learning and knowledge rests in a diversity of opinions and learning is a process of connecting specialised nodes or information sources. Siemens (2004) argues that learning theories such as behaviourism do not address learning that occurs outside of people (i.e. learning that is stored and manipulated by technology). They also fail to describe how learning happens within organisations. This is not surprising since indeed the theories were developed before technology reorganised how we live, communicate and learn. Siemens proposes “connectivism” as a learning theory for the digital age. He says:

"Connectivism is the integration of principles explored by chaos, network, and complexity and self-organization theories. Learning is a process that occurs within nebulous environments of shifting core elements - not entirely under the control of the individual. Learning (defined as actionable knowledge) can reside outside of ourselves (within an organization or a database), is focused on connecting specialized information sets, and the connections that enable us to learn more are more important than our current state of knowing.

Connectivism is driven by the understanding that decisions are based on rapidly altering foundations. New information is continually being acquired. The ability to draw distinctions between important and unimportant information is vital. The ability to recognize when new information alters the landscape based on decisions made yesterday is also critical.”

Thus, it may be argued, that learning communities, as we view them, also share attributes of Siemens' connectivist entities: learning here encourages a diversity of opinions and sharing. Specialized sources of information in different communities can be connected, with the focus on capacity building and not just on current knowledge. The groups are supportive of each other which facilitates future learning. Such notions that have been outlined in this section of the paper have influenced the design of the SPDE learning environment. In short, our view of learning communities recognizes that there is much evidence that groups and group interaction can promote learning and development. Indeed we view a learning community as a group or set of groups that carry a responsibility to promote one another's learning at an individual and group level. Our objective with the SPDE was to attempt to provide an ICT based tool to promote collaborative learning amongst our learning communities.

\section{"Collaborative Learning with Salford"}

The initiative being developed at Salford goes under the banner of "Collaborative Learning with Salford" and is being facilitated by the development of the SPDE. 
Collaborative Learning in group settings occurs across the majority of the Salford curriculum and at all levels. This style of learning has many roots including: Enterprise in Higher Education (EHE), Action Learning and Action Research, Problem Based Learning, and Practice Based Learning. This collaborative and active group learning provides the foundation for what are the learning communities. In this approach, a learning community is one that carries a responsibility to promote one another's learning. This is an active process, where learners are included in the development of Learning Content, as appropriate, and share their knowledge and experience as members of the community. The concept of a learning community can apply to staff development, curriculum development teams, subject groups, researchers, distance learners, applicants, alumni, colleges and schools, regional groups and more.

We have affixed 'with Salford' simply because with a flexible learning approach you may be learning with Salford but not necessarily at Salford ${ }^{1}$.

Every day the University has a wealth of knowledge pass through it that becomes lost to the ether. For example, imagine a room of managers from a variety of industries sharing their work-based knowledge and applying and evaluating concepts to their practice. This is an everyday occurrence, in another setting the consultancy bill for getting that shared knowledge and experience would be very large. But do we always systematically manage that knowledge and could we?

The management of the learning process and the resulting knowledge has led to the development of particular functionality in the SPDE. The SPDE enables an identified group of learners (a learning community) to be arranged around structured knowledge bases to enable quick access to and the sharing of experience and learning - both formal and informal. The community can also utilise a tutor or coach to help support community interactions; guiding members and moderating contributions. It brings informal and formal learning together, combining knowledge management and information sharing whilst building up learning through learning communities.

The SPDE also has other features that recognise the needs in a variety of circumstances for tracking skill development. For example, UK funding bodies now require that we evidence research skills development and so it provides a skill-based record of achievement as well as progress tracking. The design also recognises that many learners may wish to continue learning when they are mobile or not able to connect to the Internet. So it combines a mobile learning environment and a compatible centrally hosted facility. Learners can synchronize individual learning from their laptop or home PC. Finally, to better enable learning at the individual level the interface can adapt to suit a learners preferred approach to learning based around the Kolb learning cycle.

\section{The Salford Personal Development Environment}

In this section we shall briefly look at the features that have been included in the SPDE to help fulfill our learning community ambitions. The main operational elements are shown in Figure 1.

Figure 1 shows the notion of connected learning communities and the manner in which the SPDE interacts with the communities and the role of the Structured Knowledge Repository (SKR). The SKR is essentially a collection of knowledge and experience submitted by learners in the community in electronic format (e.g. a Word document or as an IMS/SCORM compliant learning object) and which is made accessible to other members of the community and the tutor or coach. This process enables the capture, sharing and dissemination of community generated knowledge and experience. Via a process of moderation this new learning can be added to the server content so that others may benefit.

1 Derived from comments by Bernard Lisewski, Salford University Learning Technology Group Feb 2004 


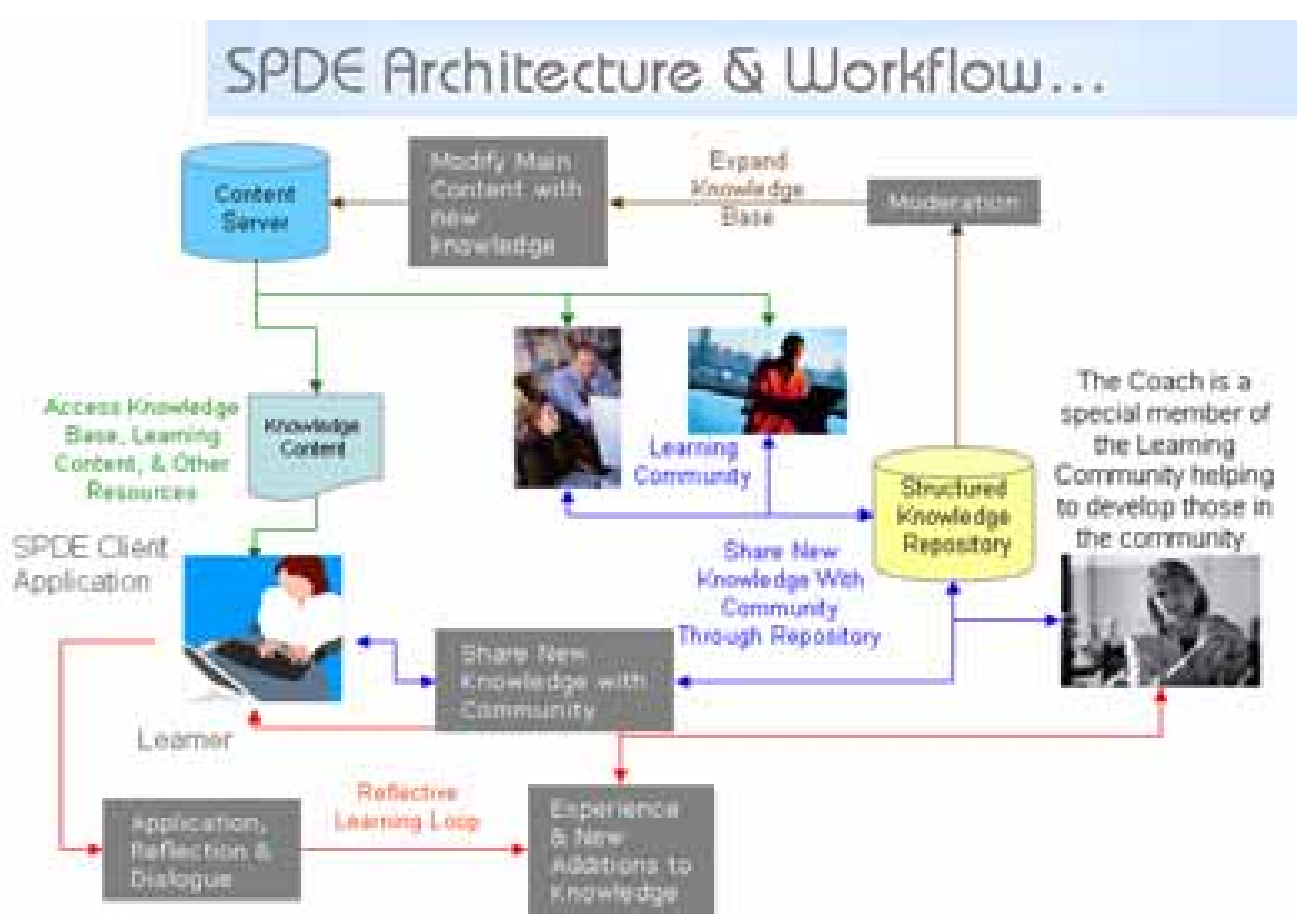

Figure 1. How SPDE interacts with connected learning communities and the role of the Structured Knowledge Repository

In summary, the SPDE enables learners and tutors, based around learning communities, to do the following:

- Tutors and learners can use the SPDE Client to easily assemble learning objects that can be structured to address a range of approaches to learning

- Tutors and learners may access a web based knowledge repository which, when used in conjunction with the SPDE, enables the collaborative development and sharing of learning content that has been enhanced by the addition of the groups experience and knowledge. Students can view and contribute to the development of such content developed and shared by staff or other students, both locally and remotely, through the Salford Shareable Knowledge Repository.

- Tutors and learners can engage in learning with the Salford PDE making use of developed content or purchased third party learning content. The Salford PDE is IMS and SCORM 1.2 compliant.

- Through engaging in learning with the Salford PDE a personal Record of Achievement is created. This can link to learning outcomes and skills framework development for auditing purposes such as PG R and T research skills or the NHS Knowledge and Skills Framework. This can link to PDPs.

The features that are essential to deliver a functioning learning community are those that allow the interaction with and the structuring and sharing of existing and new experience and knowledge. This interaction is based around members of the community and their experience as opposed to being focussed upon existing content. In the SPDE Tutors and learners have equality in the sense that both may structure and add experience and knowledge. The inbuilt functionality of the system enables this to happen. In a technical sense, to allow learners to create learning resources, the system has a simple content assembly tool that automatically packages resources (of 
any browser compatible format), should they wish to, to international e-learning standards. This means that other learners may load such content packages from the repository to share the experience of others. Ultimately such moderated packages can be placed on the server.

\section{Reflection, Sharing and the Virtual Learning Environment?}

The previous sections briefly describe the stimulus for and the developments of a learning environment to address what we consider are essential aspects of group-based learning. The SPDE does have some other features that address individual learning approaches by adapting the interface and delivery of the learning resources to match the preferred approach of the learner. The SPDE continuously monitors and adapts the interface based upon user metrics that are captured from the ordinary use of the system. This again arises from the desire to build upon what we know about individuals when learning. However, the focus of this paper is the group learning characteristics. To develop further the nature of some of the concerns for building the SPDE the following section explores aspects of related learning environment issues.

"What do virtual learning environments know about learning?” In a literal sense, absolutely nothing, just as a spreadsheet knows nothing of accountancy. However, both should have functionality that is supportive of the task they were designed for, and herein lies the rub. Are learning environments really designed for learning? Or, are they mostly the result of a set of historical and administratively convenient bits?

The answer is probably somewhere between the two all mixed in with a poor separation of subsystems within the overall system. In most learning environments there appears to be a mix'n'match of content management, learner management, and administrative processes. Within this mix there is also confusion over the functionality required to support learning, what it is and where it is. They are containers, more or less structured, for content that may or may not be tracked for access to some level. Linked to this is email. Add a collection of utilities like notepads and depositories, and probably a mechanism for synchronous and/or asynchronous discussion. These functional capabilities represent a set of useful tools under certain circumstances, but were they specifically designed for supporting learning? Of course not. So how and when should we use them and what is missing?

Simpson (2001) argues it is the interaction with the academic staff that puts the ' $L$ ' into VLE (Virtual Learning Environment). We would not dispute this. However, is this the only way of earning the ' $\mathrm{L}$ ' kite mark? This paper does not try to address the overall issue of the range of functionality required to support learning, it is too big a topic for one paper. However, we do focus on a part of this domain, that of reflective learning and the role of a community within this. The importance of reflection and reflective practice has permeated individual learning and classroom practice for many years (see Dewey, 1910; Schön, 1983, and for a critique see Bleakey, 1999), not all proponents agree about the detail but most agree that reflection is an important aspect of learning.

What do we mean by being reflective? Osterman (1990) suggested:

"Reflective practice is the mindful consideration of one's actions, specifically one's professional actions and is a challenging, focused, and critical assessment of one's behavior as a means towards developing one’s craftsmanship.” (p.134).

Reflective practice has also been described as a form of higher level cognitive activity. Valli (1992) states:

"Reflection is the capacity to 'notice oneself noticing' that is, to step back and see one's mind working in relation to its projects.” (p.99). 
The first is related to teaching and professional development, the second could apply to any activity, and they both equally apply to learning of any description.

Most definitions involve the personal exploration of the experience of learning to better develop an understanding of how to learn and so, hopefully, improve their future learning. Such characteristics as increased self-awareness and objectivity, a greater openness of approach, increased motivation, and greater independence are eschewed on the successful reflective learner.

Our approach in utilising connected Learning Communities has been to adapt and extend the environment to place learners on a similar footing to tutors. In the postgraduate taught and research arena, where we are currently exploring this development at Salford, there is much to share and to learn from each other. This approach is being piloted on a small sample of postgraduate research students this session and their tutors. Early work with research students and their supervisors, around the $\mathrm{PhD}$ Learning Agreement, has been encouraging in engaging both supervisors and students in a more interactive and meaningful dialogue. The benefits of this early work in sharing good practice and ideas about an effective learning agreement can now be re-cycled to future generations of supervisors and students via the SCR.

Increasingly research students are required to demonstrate progress against a set of skills. The collaborative approach is adding value by involving students in their learning approach and by adding to the sharing of knowledge that can be linked to the required skill sets in the SPDE and then tracked in terms of use and application for the purposes of supporting progress and evidencing engagement via a record of achievement linked to PDP.

\section{The Developing HE Environment}

An underlying imperative is to provide flexible and responsive student support structures, with institution-wide mechanisms that are capable of managing face-to-face, blended and distance learning options. This support must accommodate the full diversity of study patterns and ideally be capable of personalisation to individual student level. Alongside this will go the introduction of specific packages to support learners. The aim must be to deliver effective programmes providing learners with the opportunity to develop knowledge and skills both meaningfully and efficiently and with opportunities to effectively communicate and collaborate with others.

There will be a greater role than hitherto for self-directed learning, for peer group interactions, and for learning outcomes which relate to higher-level cognitive and interpersonal outcomes. This is judged desirable because of the ever-increasing stress on education for capability and lifelong learning, and the greater range of prior learning that mature students bring to their studies.

\section{Conclusions}

We started by identifying the drivers that we believe are powering the change in the nature of learning in HE. These also indicate that part-time and work based approaches to learning will probably grow. We have a long history at Salford, as indeed so do other HEIs, of utilising the power of group learning, and such experience may be highly relevant to the greater diversity of study modes and patterns of learning where many may not be present at Salford but working more remotely with Salford. These factors have led us to explore further the nature of a learning environment that would help enable and support the community based learning that we believe will grow.

This is work in progress and the environment is new and just being established in pilots. Early qualitative results indicate a willingness to continue to explore this approach by both staff and 
tutors. There is still much to do and we are using the feedback from these pilots to help review and revise the practice and the system. It is early days.

The Salford PDE enables learners to engage with learning objects in their own ways and order, and at their own pace. Here again, however, we envisage a rather different form of learning community, in which essentially individual learners meet with those engaged on similar quests, to discuss problems and report successes, and engage with the demands of learning in this way. All of this can build upon Salford's experience over many years of collaborative learning.

PDPs are a priority development area leading to work to tie in skills and competencies and skills gap analysis. This has been implemented to allow the mapping of Skills and Skill Sets to elearning created through the Collaborative Learning Communities, and to allow the further development of career mapping and skills gap analysis. This approach thus embodies the virtuous cycle of T\&L research driving active experimentation, by students as well as staff, which will return benefits to the practice of T\&L at Salford in terms of both providing better support for student learning and preparing students more effectively for the "real world".

\section{References}

Astin, A. W. (1993). What matters in college? Four critical years revisited. San Francisco: Jossey-Bass.

Bleakey, A. (1999). From reflective practice to holistic reflexivity. Studies in Higher Education, 24(3), 315-330.

Bruffee, K. A. (1999). Collaborative learning ( $2^{\text {nd }}$ ed.). Baltimore \& London: John Hopkins University Press.

Cole, M., John-Steiner, V, Scribner, S. \& Souberman, E. (Eds.). (1978). L. S. Vygotsky. Mind in Society: The Development of Higher Psychological Processes. Cambridge, MA: Harvard University Press.

Coleman, J. S. (1973). Youth: Transition to adulthood. Report of the Panel on Youth of the President's Science Advisory Committee, Washington, D.C: Office of Science and Technology

Dewey, J. (1910). How we think. Boston, MA: Heath and Co.

Garrison, D. R., \& Anderson, T. (2003). E-learning in the 21st century: A framework for research and practice. London \& New York: Routledge \& Falmer.

Gokhale, A. A. (1995). Collaborative learning enhances critical thinking. Journal of Technology Education, 7(1), 22-30.

Hron, A. \& Friedrich, H. F. (2003). A review of web-based collaborative learning: Factors beyond technology. Journal of Computer Assisted Learning, 19(1), 70-79.

Kuhn, T. S. (1970). Second thoughts on paradigms. The structure of scientific revolutions ( $2^{\text {nd }}$ ed.). Chicago: University of Chicago Press.

Light, R. J. (1990). The Harvard assessment seminars (First report). Cambridge, Massachusetts: Harvard University Graduate School of Education and Kennedy School of Government.

Mann, S. J. (2005). Alienation in the learning environment. Studies in Higher Education, 30(1), 43-55.

Mason, E (1970). Collaborative learning. London: Ward Lock Educational.

Oakeshott, M (1962). The voice of poetry in the conversation of mankind. Rationalism in politics. New York: Basic Books.

Osterman, K. (1990). Reflective practice: A new agenda for education. Education and Urban Society, 22(2), $133-152$.

Read, B., Archer, L. \& Leathwood, C (2003). Challenging cultures? Student conceptions of 'belonging' and 'isolation’ at a post-1992 university. Studies in Higher Education, 28(3), 261-277. 
Schön, D. A. (1983): The reflective practitioner. Basic Books. [Reprinted in 1995].

Simpson, V (2001): VE or VLE Don't forget the L! Teaching and Learning Support Unit, 5(1), Spring term, University of Surrey. Also in Association for Learning Technology Newsletter, 31, October 2000.

Siemens, G. (2004). Connectivism: A learning theory for the digital age. Retrieved October 2005 from http://www.elearnspace.org/Articles/connestivism.htm

Tang, C. (1998). Effects of collaborative learning on the quality of assignments. In B. C. Dart \& G. M. Boulton-Lewis (Eds.), Teaching and learning in higher education. Melbourne: Australian Council for Educational Research.

Valli, L. (Ed.). (1992). Reflective teacher education: Cases and critiques. Albany: State University of New York Press.

\section{Biographies}

John Rae is Professorial Fellow and Associate Dean (Teaching) in the Faculty of Business and Informatics at the University of Salford. His work is in the area of lifelong learning, educational technology, and information systems. His work is focussed on the integration teaching and learning, applied learning research, and academic enterprise activities. For many years John has worked with mature learners in workbased settings and much of the learning environment development concepts stems from this experience. John is the co-developer, with Gary Taylor, of the SPDE.

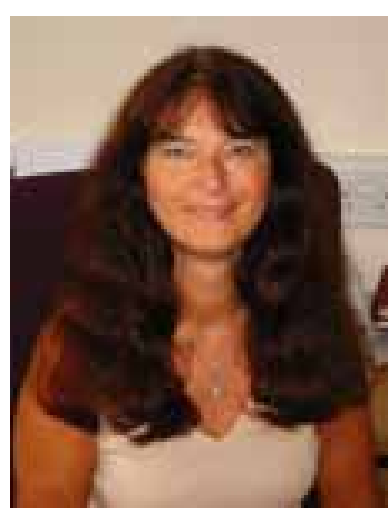

Carole Roberts is a Professor and Dean of the Faculty of Business and Informatics at the University of Salford. Her teaching interests include statistics, business forecasting and marketing research. In the past her area of research included the application of system dynamics modelling and she is a past winner of the OR Society's President's Medal. She has developed an interest in educational research and established the University's Learning \& Teaching Research Network (2001) and the Higher Education Research Centre (2002) of which she is Director.

Gary Taylor is a Project Manager and Lead Developer on several e-learning and information management projects based around the University's academic enterprise developments. His experience of learning technologies goes back over a decade and he was for several years the Team Leader of the Information Systems Institute's Flexible Learning Team. His roles have always involved the applied research and application of technology to reinforce and enhance the learning experience of staff and students, including the Salford Personal Development Environment currently in use at Salford. Gary is the co-developer, with John Rae, of the SPDE. 